\title{
The mode of ovulation in the Namaqua rock mouse, Micaelamys namaquensis
}

\author{
C.E. Relton ${ }^{1 \S}$, N.C. Bennett ${ }^{1}$, K. Medger ${ }^{1 *}$ \\ ${ }^{1}$ Mammal Research Institute (MRI), Department of Zoology and Entomology, University of Pretoria, \\ Private Bag X20, Hatfield 0028, South Africa \\ ${ }^{\S}$ CER current address: Centre for African Ecology, School of Animal, Plant and Environmental Science, \\ University of the Witwatersrand, Private Bag 3, Johannesburg 2050, South Africa
}

*Corresponding author: kmedger@zoology.up.ac.za, Tel.: +27 (0) 12420 4872, Fax: +27 (0) 12362 5242

\begin{abstract}
The pattern of ovulation in mammals is generally considered to be either spontaneous or induced by copulation, with environmental and social factors playing a key role in determining the specific mode of ovulation which would maximize the reproductive potential of the species. This study aims to determine whether the Namaqua rock mouse (Micaelamys namaquensis (A. Smith, 1834)) is a spontaneous or induced ovulator. Females were divided into 3 treatments differing in the degree of contact with a male. Namely, 7 control females had no contact with a male, a further 7 separated females had only chemical, auditory and visual contact with a male, whereas 6 females had intermittent periods of full contact with a vasectomised male. Ovarian size, follicular development, and plasma progesterone concentrations were compared between the three treatments. Penile morphology was also investigated. Corpora lutea were found in all three treatments and the penis was smooth without any ridges or spikes, indicating that $M$. namaquensis is a spontaneous ovulator. Interestingly however, the presence of a male, physical as well as just visual and olfactory, positively affected ovarian size, ovulation and plasma progesterone concentrations. This signifies that, although $M$. namaquensis ovulates spontaneously, male contact significantly influences ovulation rate and ultimately reproductive success.
\end{abstract}

Key words: Micaelamys namaquensis, Namaqua rock mouse, corpora lutea, folliculogenesis, induced ovulation, penile morphology, progesterone, spontaneous ovulation

\section{Introduction}

The timing of ovulation, the release of an ovum from a mature Graafian follicle, is vital for successful reproduction (Kauffman and Rissmann 2006). Generally two patterns of ovulation are recognised, namely spontaneous and induced (Soulsbury and lossa 2010). Spontaneous ovulation results from a continuous ovarian cycle of follicular development, whereby primordial follicles mature into primary, secondary, tertiary and finally Graafian follicles, which rupture to release the ovum (oocyte). Post ovulation, the
Graafian follicle develops into a glandular structure, the corpus luteum. Spontaneous ovulation is under the control of a cyclical production of hormones (Milligan 1974). Gonadotropin-releasing hormone $(\mathrm{GnRH})$ plays a significant role in vertebrate reproduction (Bakker and Baum 2000) by primarily stimulating the secretion of the gonadotropins, follicle stimulating hormone (FSH) and luteinizing hormone (LH), which in turn govern follicular growth and development (Campbell and Reece 2005). Whereas low estrogen levels limit the secretion of FSH and $\mathrm{LH}$ from the 
pituitary, high concentrations have an opposite effect and cause a dramatic, mid-cycle surge in $\mathrm{GnRH}$ and LH levels, which is responsible for the rupture of the Graafian follicle, the subsequent release of the ovum and development of the corpus luteum (Bakker and Baum 2000). The main function of the corpus luteum is to maintain the pregnancy in mammals by secreting progesterone (Niswender et al. 2000). A spike in progesterone concentration in the blood of a mammalian female, therefore, typically coincides with the production and development of a corpus luteum (Bouchie et al. 2006). The eventual disintegration of the corpus luteum and a drop in estrogen and progesterone levels results in liberation from the inhibitory effects and the cycle repeats itself (e.g., Herbison 2006; Jeong and Kaiser 2006).

Induced ovulators experience a similar process of follicular growth and development to that of spontaneous ovulators, but sensory stimulation of the vagina and cervix by a male during copulation is required to induce the $\mathrm{LH}$ surge and ovulation (Milligan 1980). Accordingly, induced ovulators do not show cyclic steroid-induced pre-ovulatory $\mathrm{GnRH}$ and LH surges (Bakker and Baum 2000). In induced ovulators, estrus is described as being behaviourally induced by the proximity to a male or social stimulation and the period of time before estrus may be shortened as a result of this stimulation (Conaway 1971). Males of species exhibiting induced ovulation often possess penile adaptations, such as penile spines or ridges, which may be used to stimulate the vagina and cervix of the female during copulation (Zarrow and Clark 1968; Parag et al. 2006; Faulkes et al. 2010). Penile spines, first described in the rat by SchweiggerSiedel (1866), are cornified epithelial structures on the glans of the penis and are easily viewed by electron microscopy (reviewed in Zarrow and Clark 1968). Furthermore, an ovulationinducing factor has been discovered in semen, which may aid in the stimulation of ovulation in induced ovulators such as camels, llamas and alpacas, but possibly also in spontaneous ovulators (Adams and Ratto 2013).

Several hypotheses have been proposed to explain why induced ovulation may have evolved in mammals. Firstly, many small mammals only have a short window of opportunity to reproduce, because of a seasonal breeding cycles, which is also common in southern African small mammals (Muteka et al. 2006c; Medger et al. 2010). Induced ovulation increases the chance of successful breeding after copulation (Larivière and Ferguson 2003) and decreases the likelihood of ovulation without subsequent pregnancy in seasonal breeders (Conaway 1971). Similarly, solitary species and/or species with greater home ranges and low population densities that have low mate encounter rates may benefit from induced ovulation as it eases the need for males and females to meet during the short window of female fertility (Larivière and Ferguson 2003). In light of this, induced ovulation is considered to be especially advantageous for solitary, seasonally breeding species (Larivière and Ferguson 2003; Bouchie et al. 2006). Moreover, induced ovulation has also been suggested to be beneficial for polyandrous species, for species with high juvenile mortality (Larivière and Ferguson 2003) and in female biased populations (Kauffman and Rissmann 2006).

In general, rabbits and voles are the gold standard in the study of induced ovulation (Bakker and Baum 2000; Kauffman and Rissmann 2006), whereas laboratory mice and rats are typically used to elucidate the mechanisms prevalent in spontaneous ovulators (Bronson et al. 1968). However, certain strains of mice do not ovulate unless coitus has taken place (Zarrow and Clark 1968). In addition, the field mouse, Microtus californicus (Peale, 1848), is believed to be an induced ovulator (Greenwald 1956). In reality, it is doubtful that all mammals fall perfectly into either of the two ovulatory categories. 
Conaway (1971) suggests that the pattern of ovulation should rather be viewed as a continuum, where induced ovulation and spontaneous ovulation are considered as the extremes on either end. Induced ovulation has been suggested to be the more primitive pattern (e.g., Kauffman and Rissmann 2006), but this has been disputed since spontaneous ovulation is far more common in vertebrates (Weir and Rowlands 1973).

The current study investigates the pattern of ovulation in a southern African murid rodent, the Namaqua rock mouse (Micaelamys namaquensis, previously Aethomys namaquensis (A. Smith, 1834) (Matthews and Stynder 2011)). Although $M$. namaquensis is common throughout southern Africa and is often found in large numbers and near human settlements (Muteka et al. 2006a), its ecology, physiology and behaviour are largely unknown. Furthermore, the potential of this species as an agricultural pest and vector for zoonotic diseases (Muteka et al. 2006a), emphasises the importance for studies on the reproductive biology of this rodent. To get a better understanding on the ovulation pattern of $M$. namaquensis, females were subjected to varying degrees of male contact: 1) no contact, 2) visual, olfactory and auditory contact and 3) full physical contact and the females' follicular conditions and progesterone concentrations were compared.

Reproduction of $M$. namaquensis is predominantly restricted to the spring and summer month in South Africa and both males and females are reproductively regressed during the autumn and winter months (Muteka et al. 2006a). Both seasonal reproduction and the possibly polygamous mating system (Fleming and Nicolson, 2004) may identify the Namaqua rock mouse as an induced ovulator. However, the Namaqua rock mouse is highly gregarious (Skinner and Chimimba 2005) suggesting that males and females have high encounter rates and that males may easily be able to monitor the estrous cycle of females, which may benefit a spontaneous ovulatory pattern.

\section{Materials and Methods}

Animal collection

All $M$. namaquensis were trapped in the Goro Game Reserve $\left(22^{\circ} 58^{\prime} \mathrm{S} ; 2^{\circ} 25^{\prime} \mathrm{E}\right)$ in the Soutpansberg mountainous region of the Limpopo Province of South Africa. Animals were caught using $\mathrm{H}$. B. Sherman live-traps (Tallahassee, Florida, U.S.A.) baited with peanut butter, fish and oats. The traps were set in the evening, just prior to sunset and checked in the morning, at sunrise. Fourteen males were captured in May, 3 months prior to the start of the experiment. Twenty females were collected from the same location in July (southern hemisphere winter) and housed separately to the males for 2 weeks prior to the start of the experiment. This was to enable the females an adequate time to acclimatize to their new surroundings, as well as to remove any hormonal effects induced by contact to males in their natural habitat. All animals were housed individually in polyurethane cages in climate controlled rooms with the room temperature set at $25^{\circ} \mathrm{C}$ and a humidity of 40 $60 \%$. The lighting regime was set at 14 hours of light 10 hours of dark, simulating summer conditions. Mouse pellets and water were provided ad libitum and fresh carrots, apple or hamster food was provided every second day. The enclosures were equipped with wood shavings, paper towelling and a small house for shelter.

The methodological protocol was approved by the Animal Use and Care committee of the University of Pretoria, South Africa (Ref: EC006-11) and followed the Guide to the Care and Use of Experimental Animals (Vol. 1, 2 ${ }^{\text {nd }}$ ed., 1993 and Vol. 2, 1984, Canadian Council on Animal Care, Constitution Square, Tower 2, Suite 315, 350 Albert St., Ottawa, ON K1R 1B1, Canada, http://ccac.ca). The collection of the animals was authorized under permit from the CITES and Permit Management Office, Department of Environment Affairs, 
Limpopo Province (permit number: 018CPM403-00002).

\section{Experimental design}

Experimental procedures commenced in mid August, which is the onset of the breeding season in this rodent (Muteka et al. 2006a); and lasted for a period of 35 days. Body mass was recorded to the nearest $0.01 \mathrm{~g}$ prior to the start of the experiment and at the end of the experiment. Three separate treatments were carried out:

Control: 7 females were housed singly (in cages: $34 \mathrm{~cm} \times 34 \mathrm{~cm} \times 22 \mathrm{~cm}$ ) with no males present in the same room, thus preventing any form of physical or chemical interaction between the males and females. This treatment was used as a measure for baseline hormonal concentrations and ovarian histological conditions.

2. Separated: 7 females were housed in individual cages $(48 \mathrm{~cm} \times 28.5 \mathrm{~cm} \times 45 \mathrm{~cm})$ next to seven individual non-vasectomised males. A wire mesh separated the males from the females and thus prevented any physical contact. There was, however, a visual, auditory and olfactory connection between the two sexes. These males and females remained in these conditions for the entire duration of the experiment.

3. Full contact: 6 females were each housed (in cages: $57 \mathrm{~cm} \times 48 \mathrm{~cm} \times 45 \mathrm{~cm}$ ) with individual vasectomised males. This allowed for both physical and chemical contact of the females with the males and the opportunity for copulations to occur. We, however, observed physically aggressive behaviour of the males towards the females at the beginning of the experimental period. As a result, males and females were placed together for $5 \mathrm{~h}$ every second day only. During those $5 \mathrm{~h}$, the mice were supervised in order to ensure that females were not physically harmed by the males. During periods outside of these $5 h$, the females and males were housed individually in the same climate controlled room. This ensured that the stress levels of the females were kept to a minimum, and the females were not continuously harassed by the males. If the males showed signs of harmful aggression towards the females during the $5 \mathrm{~h}$ contact period, the males were removed from the cage immediately.

Prior to the start of the experiment, all females were checked for the presence of vaginal perforation, which is an indicator of recent copulatory activity, by evaluating if the vagina was open or closed with a membrane. None of the females exhibited this trait and thus all could be considered unmated. Females of the full contact treatment were also checked for vaginal perforation immediately after they were placed with a male. Four out of the 6 females were found to have perforated vaginas and in these females, this was observed at least twice and up to 11 times indicating that $5 \mathrm{~h}$ of male contact was enough for copulations to occur.

\section{Male vasectomies}

Soon after capture, 7 of the 14 males were vasectomised under isofluorane induction by a qualified vet. The males were vasectomised in order to prevent pregnancy of the females in the full contact treatment and to obtain corpora lutea of ovulation instead of corpora lutea of pregnancy. Males were given a period of approximately 3 months to recover from surgery prior to the commencement of the experiment. This time also ensured that no traces of sperm were located within the vas deferens at the start of the experiment to avoid unwanted fertilization of the females. The vasectomised males had functional gonads and in this respect they were not different from unvasectomised males. Vasectomized $(56.5 \pm 2.8 \mathrm{~g})$ and unvasectomized $(54.5 \pm 2.6$ g) males were also of similar size (Wald $\chi^{2}=$ $0.30, d f=1, P=0.59$ ).

Ovarian histology and plasma progesterone concentrations

All females were euthanized after the conclusion of the experiments using an 
overdose of halothane anaesthetic. Immediately following death, blood was obtained directly from the heart through exsanguination and was centrifuged at $500 \mathrm{~g}$ to displace plasma from blood cells. Blood plasma was stored at $-20^{\circ} \mathrm{C}$ until analysis. The levels of plasma progesterone $(\mathrm{ng} / \mathrm{mL})$ were measured by solid-phase radioimmunoassay, using a coat-a-count kit (Diagnostic Products Corporation, Los Angeles, California, USA) and manufacturer protocol was followed. The assay was previously validated for the use on $M$. namaquensis by Muteka et al. (2006a). The intra-assay coefficient of variation was $6 \%$, and the sensitivity of the assay was $0.42 \mathrm{ng} / \mathrm{mL}$.

Post blood extraction, female reproductive systems were dissected out and preserved in Bouin's fixative for approximately $20 \mathrm{~h}$, where after they were stored in $70 \%$ ethanol. Ovaries were removed from the rest of the reproductive system and connecting tissue and the ovarian mass was recorded to the nearest $0.1 \mathrm{mg}$. The length and width of each ovary was measured using a pair of digital pocket callipers (SylvacOpto RS 232, Ultra Praeziosion Messzenge GMBH, Germany). Ovarian volume was calculated with the formula for an ellipsoid: $V=4 / 3 \pi a b^{2}$ where $a$ is one half the maximum length and $b$ is one half the maximum width of the ovary (Medger et al. 2010).

Histology of the ovaries was performed to allow the investigation of the number of ovarian follicles and corpora lutea. The ovarian samples were dehydrated using increasing concentrations of ethanol solutions in a dehydration chamber (Shandon Southern Duplex Processor, Optolabor, South Africa), embedded in paraffin wax and cut into $7 \mu \mathrm{m}$ thick sections using a microtome (American Optical, "820" Spencer). The samples were then mounted onto microscope slides and stained with Ehrlich's haematoxylin and eosin. The slides were viewed under a light microscope (Vickers Instruments AC240V, Japan) with magnification of $\times 40$ or $\times 100$.
Follicles were identified according to Bloom and Fawcett (1964). Primary and secondary follicles were viewed collectively because of their similar appearance and tertiary and Graafian follicles as well as corpora lutea were analysed separately. Follicles were identified and counted in both ovaries of each individual. The number of follicles and corpora lutea between the two ovaries was averaged for each individual; as such, the data were presented as the average number of follicles per female.

\section{Male penile morphology}

Males were euthanized using an overdose of halothane. Immediately following euthanasia, the penis was dissected out and preserved in $70 \%$ ethanol. Four penises were fixed in $10 \%$ formalin followed by a series of treatments with a $0.05 \mathrm{M}$ phosphate buffer and postfixation with $1 \%$ osmium tetraoxide. The penises were inspected using an electron microscope for the presence of penile spines or ridges, in order to determine whether any adaptation for heightened stimulation of the female during coitus is present in this species. For comparison, the penile structure of one Aethomys chrysophilus (de Winton, 1897) was inspected in the same manner.

\section{Statistical analysis}

All data was tested for normality (KolmogorovSmirnov test) and homogeneity of variance (Levene's test). Body mass of female $M$. namaquensis was log-transformed and compared between the start and end of the experiments and the treatments using a repeated-measures Analysis of Variance (RMANOVA). Apart from the number of corpora lutea and plasma progesterone concentration that were not normally distributed $(p<0.001)$ or heterogeneous $(p<0.03)$, respectively; all other variables were analyzed with Analyses of Covariance (ANCOVA) using treatment as factor and body mass at the end of the experiment as covariate. Both corpora lutea numbers and progesterone concentration were compared between treatments using 
Generalized Linear Models (GZLM). A gamma distribution with log-link function was utilized to analyse progesterone concentration and a Poisson distribution was used for corpora lutea numbers. Body mass measured at the end of the experiment was employed as covariate for all GZLMs. Post-hoc comparisons were performed using Tukey's honest significant difference (HSD) tests for all parametric analyses and least significant difference tests (LSD) for all non-parametric analyses. All statistical analyses were performed using IBM SPSS Statistics version 20.0 (IBM Corporation). All results are presented as mean \pm standard error and significance is assumed at $P \leq 0.05$.

\section{Results}

Body mass

Body mass of female $M$. namaquensis was not significantly different between the treatments $\left(F_{2,17}=3.15, P=0.07\right)$. It, however, increased significantly from the beginning to the end of the experiment $\left(F_{1,17}=99.98, P<0.001\right)$. Overall, females gained $10.53 \pm 1.29 \mathrm{~g}$ throughout the experiment and the mass gained was comparable between the control $(11.48 \pm 2.17 \mathrm{~g})$, separated $(10.46 \pm 2.17 \mathrm{~g})$ and full contact treatments $\left(9.65 \pm 2.35 \mathrm{~g} ; F_{2,17}=\right.$ 1.29, $P=0.30$, Fig. 1 ).

\section{Ovaries and progesterone}

Ovarian volume was positively related to body mass $\left(F_{1,16}=57.53, P=0.03\right)$ and the standard residuals were calculated for further analysis. The number of corpora lutea was also positively related to body mass (Wald $\chi^{2}=8.79$, $d f=1, P=0.003)$. There was no significant relationship between body mass and ovarian mass or any of the follicles $\left(F_{1,16}<2.56, P>\right.$ $0.13)$, and body mass and plasma progesterone concentration (Wald $\chi^{2}=0.30, d f=1, P=0.59$ ).

Ovarian mass and volume were significantly different between the treatments $\left(F_{1,17}<8.68, P>0.003\right)$. Control females had significantly smaller ovarian mass and volume than full contact females (Tukey's-HSD: $P=$ 0.002 ; Fig. 2). Ovarian mass and volume was similar between control and separated females (Tukey's-HSD: $P>0.20$ ). Ovarian volume was not significantly different between separated and full contact females (Tukey's-HSD: $P=$ 0.07), whereas ovarian mass was significantly larger in full contact than separated females (Tukey's-HSD: $P=0.03$; Fig. 2). Plasma progesterone concentration was significantly different between treatments (Wald $\chi^{2}=10.00$, $d f=2, P=0.007$ ), being significantly larger in full contact and separated females than control females (LSD: $P<0.05$; Fig. 3). Progesterone concentration was not significantly different between separated and full contact females (LSD: $P=0.57$; Fig. 3).

The numbers of primary/secondary, tertiary and Graafian follicles did not differ significantly between treatments $\left(F_{1,16}<1.09, P\right.$ $>0.36$; Table 1). Although corpora lutea were observed in all treatments, they were found in only 1 out of 7 females of the control treatment, but in 3 out of 7 or 6 females of the separated and full contact treatments, respectively. In addition, corpora lutea numbers were significantly different between treatments (Wald $\chi^{2}=11.59, d f=1, P=0.003$ ), and significantly more corpora lutea were counted in the separated and full contact treatments than the control treatment (LSD: $P$ $\leq$ 0.02; Table 1). Numbers of corpora lutea were comparable for separated and paired females (LSD: $P=0.22$; Table 1 ).

\section{Penile morphology}

The glans penis of $M$. namaquensis was very smooth and we did not find any indication for spines or ridges on the penile surface (Fig. 4a, c and e). In comparison, the closely related $A$. chrysophilus did possess penile spines along the surface of its penis (Fig. 4b, $d$ and f).

\section{Discussion}

The presence of corpora lutea within the ovaries of separated and control females indicates that ovulation took place without prior copulation with a male. The plasma progesterone concentrations mirrored the 
results of corpora lutea prevalence between treatments, thus confirming that the act of coitus was not necessary for the development of corpora lutea and the resulting release of progesterone. This strongly implies that $M$. namaquensis is a spontaneous ovulator. Additionally, the absence of spines or ridges on the penile surface of male $M$. namaquensis complements the proposed spontaneous ovulatory trait in this species.

Spines or ridges are evident on the penises of a number of induced ovulators and provide cervico-vaginal stimulation to the female, thus aiding in the induction of ovulation during copulation (Zarrow and Clark 1968; Van Sandwyk and Bennett 2005). Although no penile spines or ridges were observed in $M$. namaquensis, some spines were observed in the closely related $A$. chrysophilus, which may be an indication of the importance of copulatory stimulation for ovulation in this species.

Spontaneous ovulation, combined with a short luteal phase in females that have not copulated, has been described in several groups of rodents within the families Muridae and Cricetidae (Conaway 1971), and it is not surprising that $M$. namaquensis also exhibits this trait. Conaway (1971) suggests that this is an adaptation for species that are highly preyed upon and exhibit short life cycles like many African murids including $M$. namaquensis. The Muridae is the largest of all mammalian families with over one thousand described species widely distributed across the globe (Musser and Carleton 2005) and most are spontaneous ovulators (Voss 1979). For example, the corn mouse (Calomys musculinus (Thomas, 1913)) from South America is a spontaneous ovulator with a two or three day luteal phase (Buzzio and Castro-Vázquez 2002) as are most laboratory species such as rats and mice (e.g., Kauffman and Rissmann 2006). On the other hand, induced ovulation is thought to be a general feature in the order Insectivora and in the Sciuridae and Arvicolinae of the order Rodentia (Conaway 1971). In rodents, induced ovulation is especially common in lemmings and voles (Breed 1972; Hasler et al. 1974). The degree of stimulation required for reproductive development and ovulation, however, varies markedly between different vole species and is thought to be affected by environmental stimuli and the social structure of a species (Gray et al. 1974; Solomon et al. 1996). In monogamous voles the mere presence of a male odor appears to be sufficient to induce estrus and ovulation in at least some females (Milligan 1974), whereas mating seems to be required for behavioural estrus and successful ovulation in promiscuous vole species (Roberts et al. 1999).

Although $M$. namaquensis appears to be a spontaneous ovulator, the presence of a male largely influenced female ovarian size, structure and function. Ovarian size, corpora lutea numbers and progesterone concentration were clearly increased in females that had contact to a male. Although a direct physical contact had a more pronounced effect on ovarian size, pure visual and olfactory contact was sufficient for increased development of corpora lutea and secretion of progesterone. This illustrates that a visual and olfactory contact, which is most likely facilitated by male pheromones, positively affects ovulation of female M. namaquensis, even in the absence of copulatory behaviour. Olfaction is very important for reproduction in most mammals, including rodents and humans, and the main as well as the accessory olfactory system play an important role (Moffatt 2003). The accessory olfactory system, which is located in the vomeronasal organ, appears to be especially important for the onset of puberty, behavioural estrus and ovulation through male odors. In mice (Mus musculus Linnaeus, 1758), for example, the vomeronasal organ is required for the female to become sexually receptive (Keller et al. 2006). In prairie voles (Microtus ochrogaster (Wagner, 1842)), a direct contact of male urine with the female's upper lip is required for reproductive development 
suggesting the involvement of the vomeronasal organ (Carter et al. 1980). A similar mechanism is likely to facilitate reproductive development and ovulation in $M$. namaquensis. Although the females were separated from the males, contact with male urine was possible and has likely advanced reproductive development in the separated female group. It is, however, not clear if other cues from the male as well as volatile cues are sufficient to induce ovulation in $M$. namaquensis. It should also be noted that male contact only appeared to influence ovulation and not folliculogenesis as all females exhibited similar numbers of mature follicles. Male $M$. namaquensis were found to be reproductively photoresponsive to long-day photoperiods (Muteka et al. 2006b), and it is likely that females are as well. The photoperiodic conditions in the present study may, therefore, have contributed to similar follicular development in all females. Although the reproductive state of an individual is influenced considerably by environmental conditions and resources; social signals, such as pheromones, from both males and females, can supply additional knowledge to the individual about when the timing of reproductive activities might be most beneficial ( (Kiester and Slatkin 1974; Emlen and Demong 1975).

The highly gregarious nature of $M$. namaquensis (Fleming and Nicolson 2004), and the resulting high encounter rates between males and females could possibly be an important factor which allows for spontaneous ovulation. However, since M. namaquensis is a seasonal breeder, has a short life span (Muteka et al. 2006a) and high mortality (Skinner and Chimimba 2005); it is vital that these rodents maximize their reproductive potential and conserve energy whenever possible. Therefore, M. namaquensis, like other murids, should have a short luteal phase and thus be able to return to a state of estrous soon after unfertilized ovulation. Additionally, we have shown that in the absence of a prospective mate the females show reduced ovulation in comparison to when males were present. This trait could possibly be attributed to the high cost of female reproductive processes (Gwazdauskas et al. 2000). In the absence of a male, the estrous cycle could be suppressed or halted, in order to prevent unnecessary energy expenditure. Muteka et al. (2006a) reported that Graafian follicles and corpora lutea were only found within the ovaries of females during the breeding months (i.e. September to March). Food is limited during the winter months, therefore it is suggested that the lack of breeding during winter permits the animal to concentrate its energy stores on other physiological requirements, for example thermogenesis, cellular growth and repair, as well as locomotion (Muteka et al. 2006a). Due to the energetic cost of ovulation and folliculogenesis (Gwazdauskas et al. 2000), we predict that in the absence of a male, female M. namaquensis would react in a similar manner to that of winter reproductive conditions and thus redirect energy expenditure away from reproductive processes and towards other bodily functions. This could explain the lack of corpora lutea and lowered plasma progesterone concentrations in the majority of the control females. It is important to note that females were fed ad libitum, they all increased in mass during the experiment and large amounts of fat were observed in their bodies. This indicates that even when energetic resources are abundant, as well as photoperiod and temperatures reflecting those of the breeding season, the absence of a male will still have a strong impact on the estrous cycle and the growth and development of corpora lutea in female $M$. namaquensis.

In conclusion, it is evident from this and other studies (Muteka et al. 2006b) that reproductive onset, estrous cyclicity and ovulation of $M$. namaquensis can be influenced by a number of environmental and social factors such as temperature, photoperiod, food availability, social structure and the chemical contact between the sexes. Micaelamys namaquensis is a spontaneous ovulator as 
demonstrated by the occurrence of corpora lutea in females without male contact and the lack of penile spines. Spontaneous ovulation may be especially beneficial in this species as it is gregarious and has high male encounter rates. Still reproductive development of females is affected by environmental conditions and male contact appears to be of considerable importance for reproductive development and ovulation. Additionally, we agree with Conaway (1971) and several other authors that the mode of ovulation should be viewed as a continuum of possible phenomena rather than as two clearly defined and steadfast categories.

\section{Acknowledgments}

The study was funded by a South African Research Chair for mammalian behavioural ecology and physiology awarded to N.C. Bennett by the National Research Foundation (NRF). K. Medger acknowledges funding from the University of Pretoria for postdoctoral research. Ruan de Bruin, Carol Hoole, Kemba Butler, Shaun D'Araujo, Sasha Hoffmann, Nico Lübcker and Low de Vries are acknowledged for their assistance and support during this study. Dave Dewsnap from the Goro Game Reserve is thanked for his support.

\section{References}

Adams, G.P., \& Ratto, M.H. 2013. Ovulationinducing factor in seminal plasma: a review. Anim. Reprod. Sci. 136(3): 148156. doi:10.1016/j.anireprosci.2012.10.004.

Bakker, J., and Baum, M.J. 2000. Neuroendocrine regulation of $\mathrm{GnRH}$ release in induced ovulators. Front. Neuroendocrinol. 21(3): 220-262. doi:10.1006/frne.2000.0198.

Bloom, W., and Fawcett, D.W. 1964. A textbook of histology. 8th ed. W. B. Saunders Company, Philadelphia, London.

Bouchie, L., Bennett, N.C., Jackson, T., and J. M. Waterman. 2006. Are Cape ground squirrels (Xerus inauris) induced or spontaneous ovulators? J. Mammal. 87(1): 60-66. doi:10.1644/04-MAMM-A192R1.1.

Breed, W.G. 1972. The question of induced ovulation in wild voles. J. Mammal. 53(1): 185-187. doi: 10.2307/1378841.

Bronson, F.H., Dagg, C.P., and Snell, G.D. 1968. Chapter 11 - Reproduction. In Biology of the laboratory mouse. Edited by E.L. Green. 2nd ed. Dover Publication, Inc., New York. pp. 1-26.

Buzzio, O.L., and Castro-Vázquez, A. 2002. The reproductive biology of the corn mouse, Calomys musculinus, a neotropical sigmodontine. J. Neotrop. Mammal. 9: 135-158.

Campbell, N.A., and Reece, J.B. 2005. Biology. 7th ed. Pearson Benjamin Cummings, Cape Town.

Carter, C.S., Getz, L.L., Gavish, L.J., McDermott, L., and Arnold, P. 1980. Male-related pheromones and the activation of female reproduction in the prairie vole (Microtus ochrogaster). Biol. Reprod. 23(5): 10381045. doi:10.1095/biolreprod23.5.1038.

Conaway, C.H. 1971. Ecological adaptation and mammalian reproduction. Biol. Reprod. 4(3): 239-247.

Emlen, S.T., and Demong, N.J. 1975. Adaptive significance of synchronized breeding in a colonial bird: a new hypothesis. Science, 188(4192): 1029-1031. doi:10.1126/science.1145188.

Faulkes, C.G., Sichilima, A.M., Van Sandwyk, J., Lutermann, H., and Bennett, N.C. 2010. Control of ovulation in female giant molerats Fukomys mechowii (Rodentia: Bathyergidae), and phylogenetic trends within the family. J. Zool. (Lond.) 282(1): 64-74. doi:10.1111/j.1469-7998.2010.00713.x

Fleming, P.A., and Nicolson, S.W. 2004. Sex differences in space use, body condition and survivorship during the breeding season in the Namaqua rock mouse, Aethomys namaquensis. Afr. Zool. 39(1): 123-132. 
Gray, G.D., Davis, H.N., Zerylnick, M., and Dewsbury, D.A. 1974. Oestrus and induced ovulation in montane voles. J. Reprod. Fertil. 38(1): 193-196.

Greenwald, G.S. 1956. The reproductive cycle of the field mouse, Microtus californicus. J. Mammal. 37(2): 213-222.

Gwazdauskas, F.C., Kendrick, K.W., Pryor, A.W., and Bailey, T.L.. 2000. Impact of follicular aspiration on folliculogenesis as influenced by dietary energy and stage of lactation. J. Dairy Sci. 83(7): 1625-1634.

Hasler, J.F., Dziuk, P.J., and Banks, E.M. 1974. Ovulation and related phenomena in the collared lemming (Dicrostonyx groenlandicus). J. Reprod. Fertil. 38(1): 21-28.

Herbison, A.E. 2006. Physiology of the gonadotropin-releasing hormone neuronal network. In Knobil and Neill's Physiology of Reproduction. Edited by J.D. Neill. 3rd ed. Elsevier, Virginia. pp. 1415-1483.

Jeong, K.-H., and Kaiser, U.B. 2006. Gonadotropin-releasing hormone regulation of gonadotropin biosynthesis and secretion. In Knobil and Neill's Physiology of Reproduction. Edited by J.D. Neill. 3rd ed. Elsevier, Virginia. pp. 1635-1701.

Kauffman, A.S., and Rissmann, E.F. 2006. Neuroendocrine control of matinginduced ovulation. In Knobil and Neill's Physiology of Reproduction. Edited by J.D. Neill. 3rd ed. Elsevier, Virginia. pp. 2283-2318.

Keller, M., Pierman, S., Douhard, Q., Baum, M.J., and Bakker, J. 2006. The vomeronasal organ is required for the expression of lordosis behaviour, but not sex discrimination in female mice. Eur. J. Neurosci. 23(2): 521-530. doi:10.1111/j.1460-9568.2005.04589.x.

Kiester, A.R., and Slatkin, M. 1974. A strategy of movement and resource utilization. Theor. Popul. Biol. 6(1): 1-20. doi:10.1016/0040-5809(74)90028-8.
Larivière, S., and Ferguson, S.H. 2003. Evolution of induced ovulation in North American carnivores. J.Mammal. 84(3): 937-947. doi:10.1644/BME-003.

Matthews, T., and Stynder, D.D. 2011. An analysis of the Aethomys (Murinae) community from Langebaanweg (Early Pliocene, South Africa) using geometric morphometrics. Palaeogeogr. Palaeoclimatol. Palaeoecol. 302(3-4): 230-242. doi:10.1016/j.palaeo.2011.02.003.

Medger, K., Chimimba, C.T., and Bennett, N.C. 2010. Seasonal reproduction in the female spiny mouse from South Africa. J. Zool. (Lond.) 282(3): 163-170. doi:10.1111/j.1469-7998.2010.00726.x.

Milligan, S.R. 1974. Social environment and ovulation in the vole, Microtus agrestis. J. Reprod. Fertil. 41(1): 35-47.

Milligan, S.R. 1980. Pheromones and rodent reproductive physiology. Symp. Zool. Soc. Lond. 45: 251-275.

Moffatt, C.A. 2003. Steroid hormone modulation of olfactory processing in the context of socio-sexual behaviors in rodents and humans. Brain Res. Rev. 43(2): 192-206. doi:10.1016/S01650173(03)00208-X.

Musser, G.G., and Carleton, M.D. 2005. Superfamily Muroidea. In Mammal species of the world. Edited by D.E. Wilson and D.M. Reeder. 3rd ed. The Johns Hopkins University Press, Baltimore. pp. 894-1531.

Muteka, S.P., Chimimba, C.T., and Bennett, N.C. 2006a. Reproductive seasonality in Aethomys namaquensis (Rodentia: Muridae) from southern Africa. J. Mammal. 87(1): 67-74. doi:10.1644/05MAMM-A-088R2.1.

Muteka, S.P., Chimimba, C.T., and Bennett, N.C. 2006b.

Reproductive photoresponsiveness in Aethomys ineptus and $A$. namaquensis (Rodentia: Muridae) from southern Africa. J. Zool. (Lond.) 268(3): 225-231. doi:10.1111/j.1469-7998.2005.00022.x. 
Muteka, S.P., Chimimba, C.T., and Bennett, N.C. 2006c. Reproductive seasonality in the Tete veld rat (Aethomys ineptus) (Rodentia: Muridae) from southern Africa. J. Zool. (Lond.) 270(2): 314-322. doi:10.1111/j.1469-7998.2006.00140.x.

Niswender, G.D., Juengel, J.L., Silva, P.J., Rollyson, M.K., and McIntush, E.W. 2000. Mechanisms controlling the function and life span of the corpus luteum. Physiol. Rev. 80(1): 1-29.

Parag, A., Bennett, N.C., Faulkes, C.G., and Bateman, P.W. 2006. Penile morphology of African mole rats (Bathyergidae): structural modification in relation to mode of ovulation and degree of sociality. J. Zool. (Lond.) 270(2): 323-329. doi:10.1111/j.1469-7998.2006.00141.x.

Roberts, R.L., Wolf, K.N., Sprangel, M.E., Rall, W.F., and Wildt, D.E.. 1999. Prolonged mating in prairie voles (Microtus ochrogaster) increases likelihood of ovulation and embryo number. Biol. Reprod. 60(3): 756-762. doi:10.1095/biolreprod60.3.756.

Skinner, J.D., and Chimimba, C.T. 2005. The mammals of the southern African subregion. 3rd ed. Cambridge University Press, Cambridge.

Solomon, N.G., Vandenbergh, J.G., Wekesa, K.S., and Barghusen, L. 1996. Chemical cues are necessary but insufficient for reproductive activation of female pine voles (Microtus pinetorum). Biol. Reprod. 54(5): 1038-1045.

doi:10.1095/biolreprod54.5.1038.

Soulsbury, C.D., and lossa, G. 2010. The impact of ovulation mode on sperm quantity and quality in mammals. Evol. Ecol. 24(4): 879-889. doi:10.1007/s10682-009-9344$y$.

Van Sandwyk, J.H.d.T., and Bennett, N.C. 2005. Do solitary, seismic signalling Cape molerats (Georychus capensis) demonstrate spontaneous or induced ovulation? J. Zool. (Lond.) 267: 75-80. doi:10.1017/S0952836905007302.

Voss, R.S. 1979. Male accessory glands and the evolution of copulatory plugs in rodents. Occas. Pap. Mus. Zool. Univ. Mich. No. 689: 1-27.

Weir, B.J., and Rowlands, I.W. 1973. Reproductive strategies of mammals. Annu. Rev. Ecol. Syst. 4: 139-163.

Zarrow, M.X., and Clark, J.H. 1968. Ovulation following vaginal stimulation in a spontaneous ovulator and its implications. J. Endocrinol. 40(3): 343352. doi:10.1677/joe.0.0400343. 


\section{Table}

Table 1. Quantitative histology of the ovaries of Micaelamys namaquensis after 5 weeks of experimental treatment, mean number of follicles and corpora lutea \pm SE per ovary for control, separated and full contact treatments.

\begin{tabular}{lccccc}
\hline Treatment & $\mathrm{n}$ & $\begin{array}{c}\text { Primary and } \\
\text { Secondary follicles }\end{array}$ & $\begin{array}{c}\text { Tertiary } \\
\text { follicles }\end{array}$ & $\begin{array}{c}\text { Graafian } \\
\text { follicles }\end{array}$ & Corpora lutea \\
\hline Control & 7 & $54.71 \pm 8.37$ & $10.43 \pm 2.04$ & $5.29 \pm 1.19$ & $0.14 \pm 0.85$ \\
Separated & 7 & $64.43 \pm 8.87$ & $13.71 \pm 2.04$ & $7.43 \pm 1.19$ & $1.86 \pm 0.85$ \\
Full contact & 6 & $67.50 \pm 9.04$ & $10.42 \pm 2.20$ & $5.58 \pm 1.29$ & $1.83 \pm 0.92$ \\
\hline
\end{tabular}




\section{Figures}

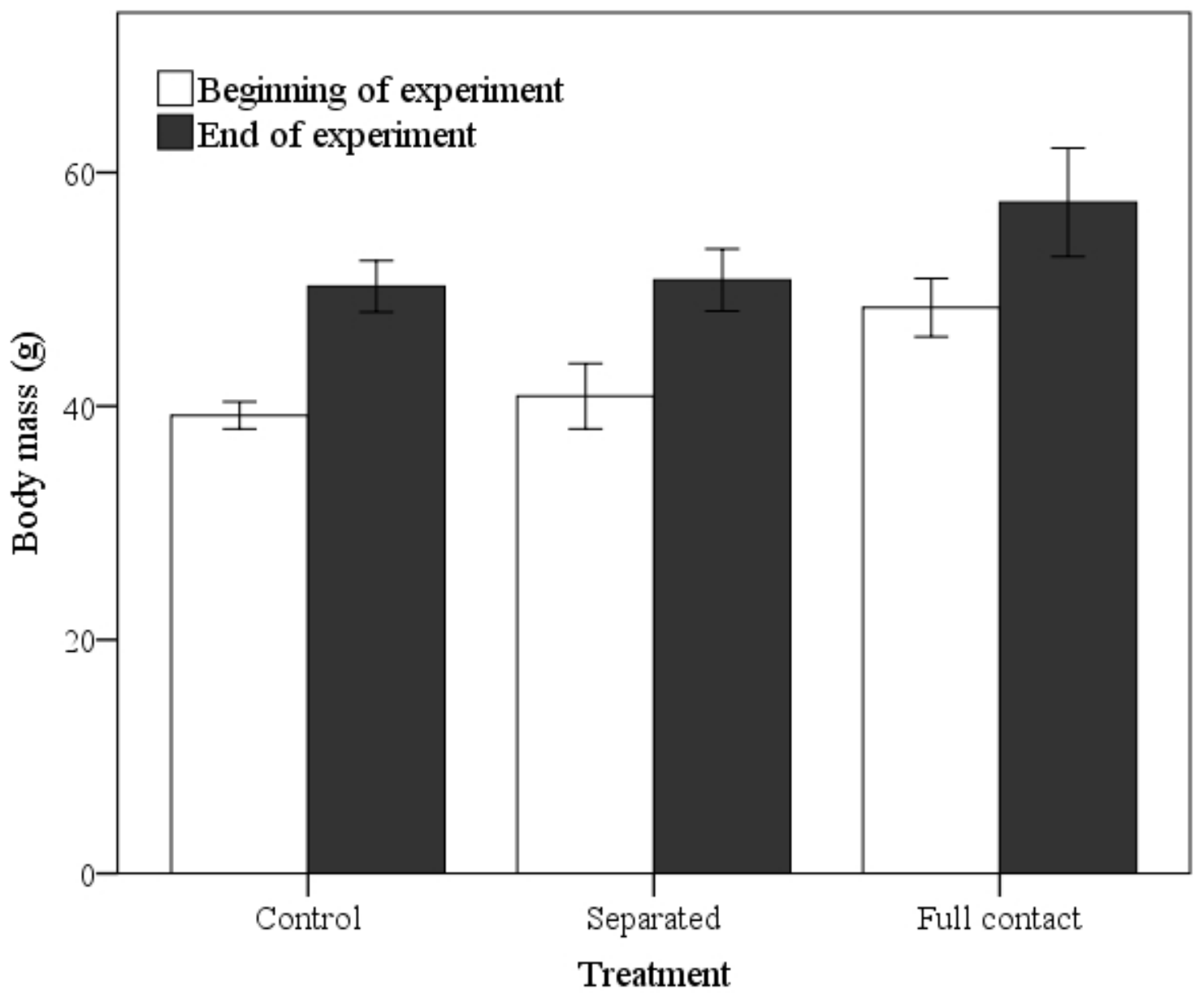

Fig. 1. Body mass (g) of female Micaelamys namaquensis either without any contact to a male (control), with auditory and visual contact with a male (separated) or full contact with a male (full contact) and at the beginning and end of the experiment for each treatment. Results are mean $\pm \mathrm{SE}$. 

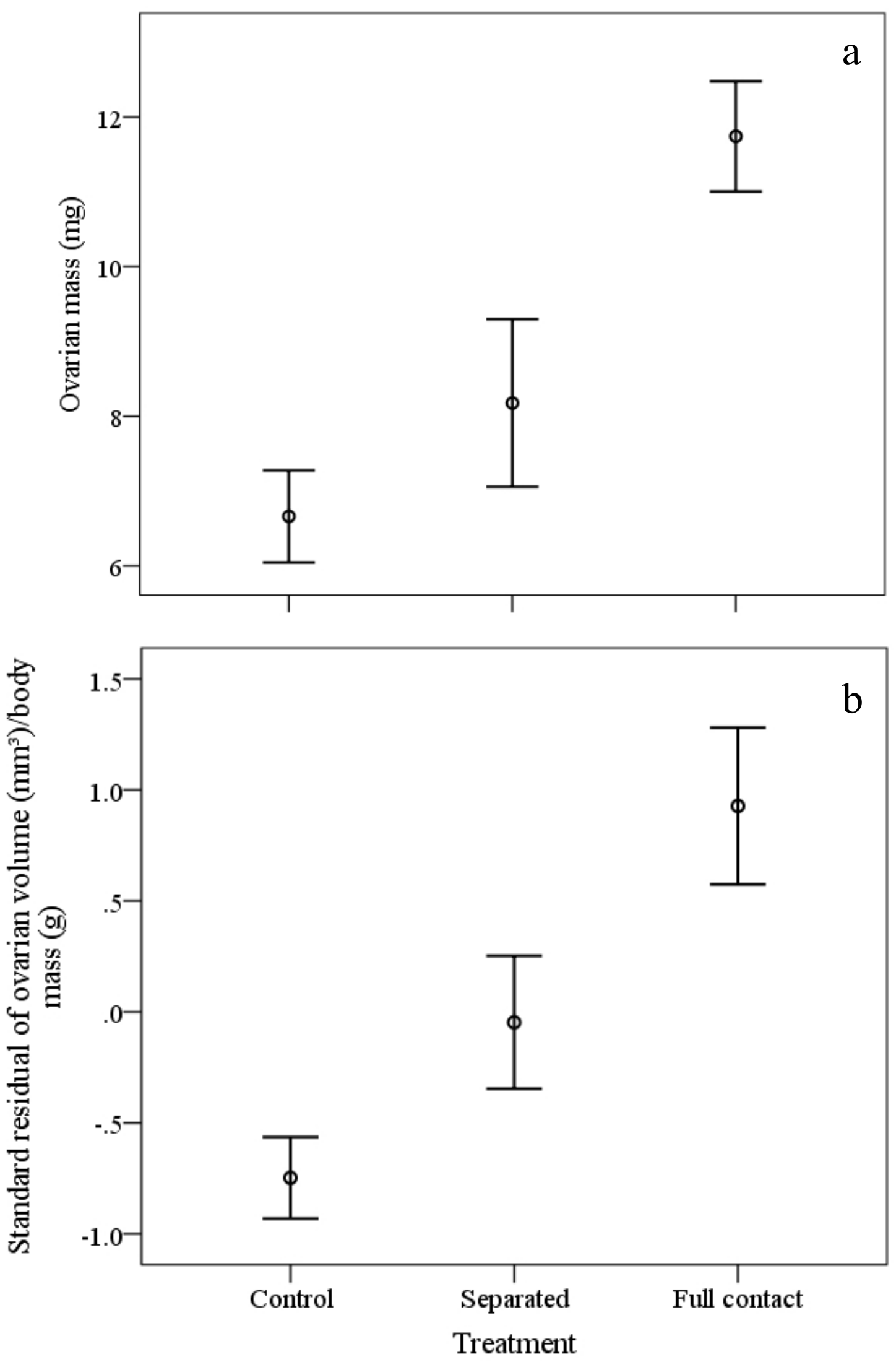

Fig. 2. Ovarian mass (mg) (a) and standard residual of ovarian volume $\left(\mathrm{mm}^{3}\right)$ by body mass (g) (b) of female M. namaquensis subjected to full physical contact with a male (full contact), only olfactory, auditory and visual contact with a male (separated) and no contact with a male (control). Results are mean $\pm \mathrm{SE}$. 


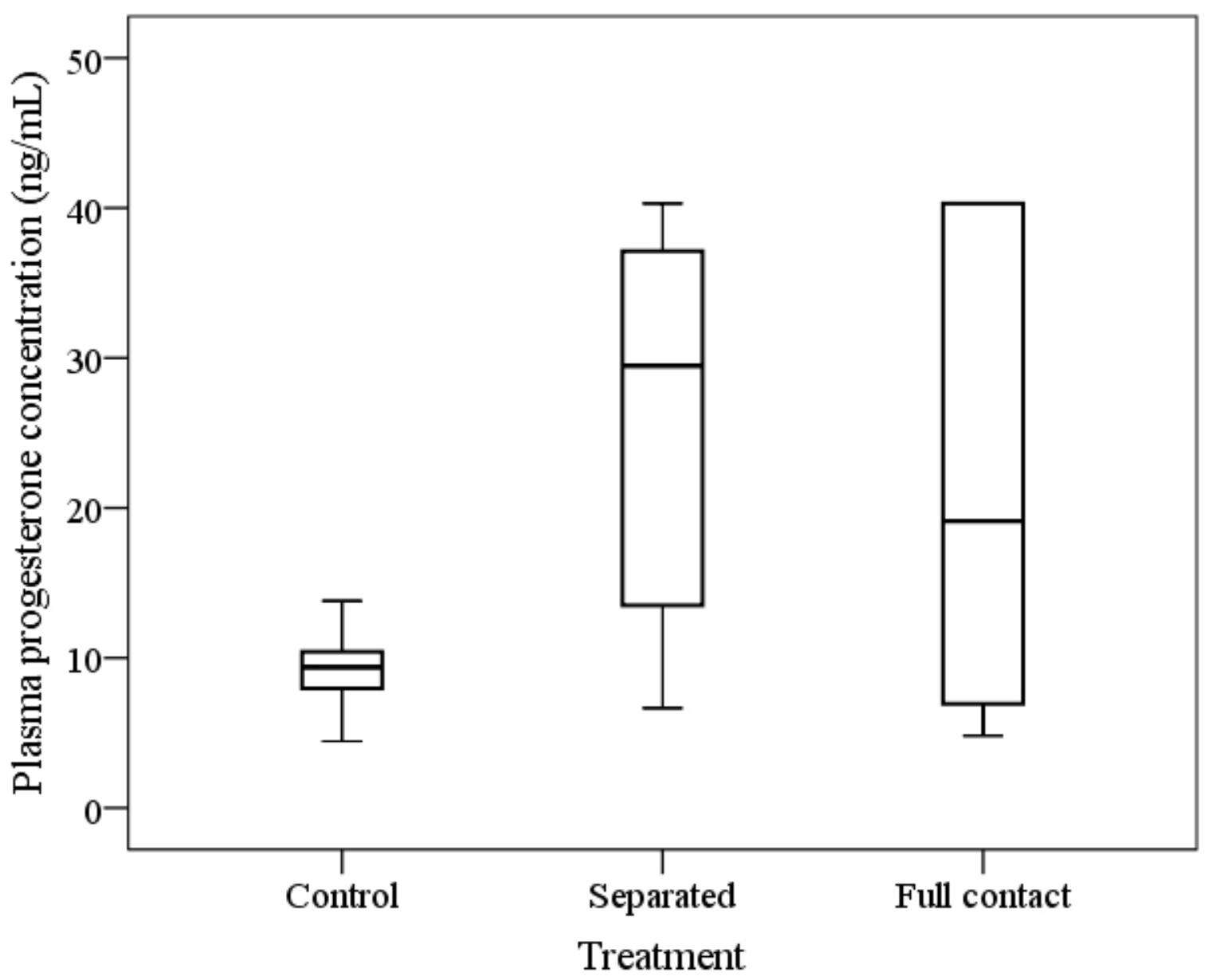

Fig. 3. Box plot showing plasma progesterone concentration of female $M$. namaquensis subjected to three different conditions of male contact: without contact (control), olfactory, auditory and visual contact (separated) and full physical contact (full contact). 

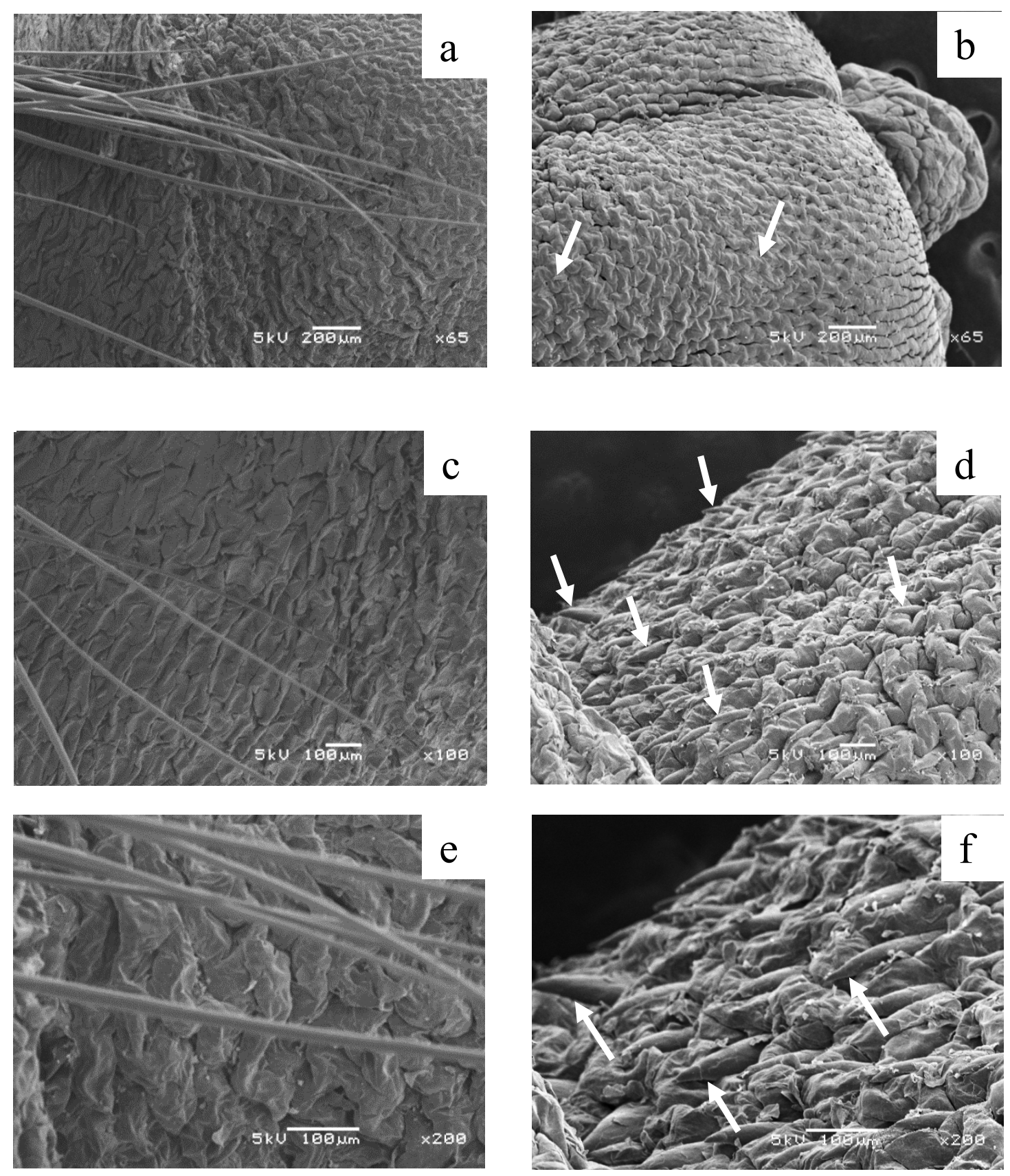

Fig. 4. Scanning electron micrographs showing the morphology of the glans penis of Micaelamys namaquensis ( $\mathrm{a}, \mathrm{c}$ and $\mathrm{e}$ ) and Aethomys chrysophilus (b, d and f). Some hairs can be seen in $M$. namaquensis. Penile spines (arrows) are evident in A. chrysophilus, but not $M$. namaquensis. 